\title{
Temperature effect of electronic nose sampling for classifying mixture of beef and pork
}

\author{
Sinarring Azi Laga ${ }^{1}$, Riyanarto Sarno ${ }^{2}$ \\ ${ }^{1}$ Sekolah Tinggi Ilmu Ekonomi Perbanas, Indonesia \\ ${ }^{2}$ Department of Informatics, Institut Teknologi Sepuluh Nopember, Indonesia
}

\section{Article Info \\ Article history: \\ Received Sep 1, 2019 \\ Revised Mar 15, 2020 \\ Accepted Apr 9, 2020 \\ Keywords: \\ Beef \\ Classification \\ Electronic Nose \\ $\mathrm{k}-\mathrm{NN}$ \\ Naïve Bayes \\ Pork \\ Random Forest}

\begin{abstract}
Strong demand and strong price of raw foodstuffs like beef was commonly used in conventional markets by beef dealers to commit fraud in order to gain larger income. The fraud has been in the form of combining beef and pork. In Indonesia, this has been a issue of food health in recent years. Via scent, some food safety concerns can be expected. By using electronic nose that is equipped with electrochemical and air sensors such as temperature sensors, strain, and humidity to find the pure beef or mixed beef. According to its selectivity, the sensor can detect gas to make small icurrents that are the result of chemical sensor and gas interactions with oxygen. In this study, the classification method k-NN, SVM, Naïve Bayes, and Random Forest was used in 5 different meat variations with a ratio of $0 \%, 10 \%, 50 \%, 90 \%$ and $100 \%$ with temperatures of $-22^{\circ} \mathrm{C}$, Room Temp., And $55^{\circ} \mathrm{C}$. The results showed the effect of temperature on increasing the accuracy, which is at a temperature of $-22^{\circ} \mathrm{C}$. The lower the temperature, the more stable the value obtained by electronic nose. At a temperature of $-22^{\circ} \mathrm{C}$, the method that produces the highest accuracy is the Random Forest method.
\end{abstract}

Copyright $\odot 2020$ Institute of Advanced Engineering and Science. All rights reserved.

\section{Corresponding Author:}

Sinarring Azi Laga,

Sekolah Tinggi Ilmu Ekonomi Perbanas,

Jalan Nginden Semolo No.34-36, Ngenden Jangkungan, Sukolilo, Surabaya, 60118, Indonesia.

Email: sinarring.laga @ perbanas.ac.id

\section{INTRODUCTION}

Strong demand and strong price of raw foodstuffs like beef was commonly used in conventional markets by beef dealers committing deception to gain more income. The fraud took the form of combining beef and pork [1]. In Indonesia, this has been a issue of food health in recent years. Via scent, some food safety concerns can be expected. By using electronic nose that is equipped with electrochemical and air sensors such as temperature sensors, strain, and humidity to find the pure beef or mixed beef. Food protection and insurance cover a variety of things like nutrition, sanitation and legality [2]. The creation of blending beef and pork is often practiced in fresh state. It occurs because pork is an inexpensive animal protein source, and is readily available on the market, making it beef scam more lucrative for the rogue seller. The case of this mixed beef poses significant questions, given that Indonesia is the world's largest nation with a Muslim majority. However, certain classes of people are hypersensitive, too or aversion to pork [3]. Their scent can discern certain food safety issues.

By using electronic nose that is equipped with electrochemical and air sensors such as temperature sensors, strain, and humidity to find the pure beef or mixed beef [4]. Depending on its selectivity, the sensor can detect gas by generating low currents which result from chemical sensor reations and gas between oxygen [5]. In this research, further analyzes using algorithms for machine learning algorithms with 3 temperature differences in each of the 5 variations of sample meat data was applied to determine optimum classification result. The temperature used were the temperature of $-22^{\circ} \mathrm{C}$, Room Temp And $55^{\circ} \mathrm{C}$, while the variation of the meat mixture used were 0\% Beef - 100\% Pork; Beef 10\% - Pork 90\%; Beef 50\% - Pork 50\%; 
Beef $90 \%$ - Pork 10\%; and 100\% Beef - 0\% Pork. The algorithms used for machine learnig is k-Nearest Neighbor (k-NN), Support Vector Machine (SVM), Naïve Bayes, dan Random Forest.

\section{RESEARCH METHOD}

The research methodology was organized systematically as an analysis process. This is the phases used for the study as shown in Figure 1.

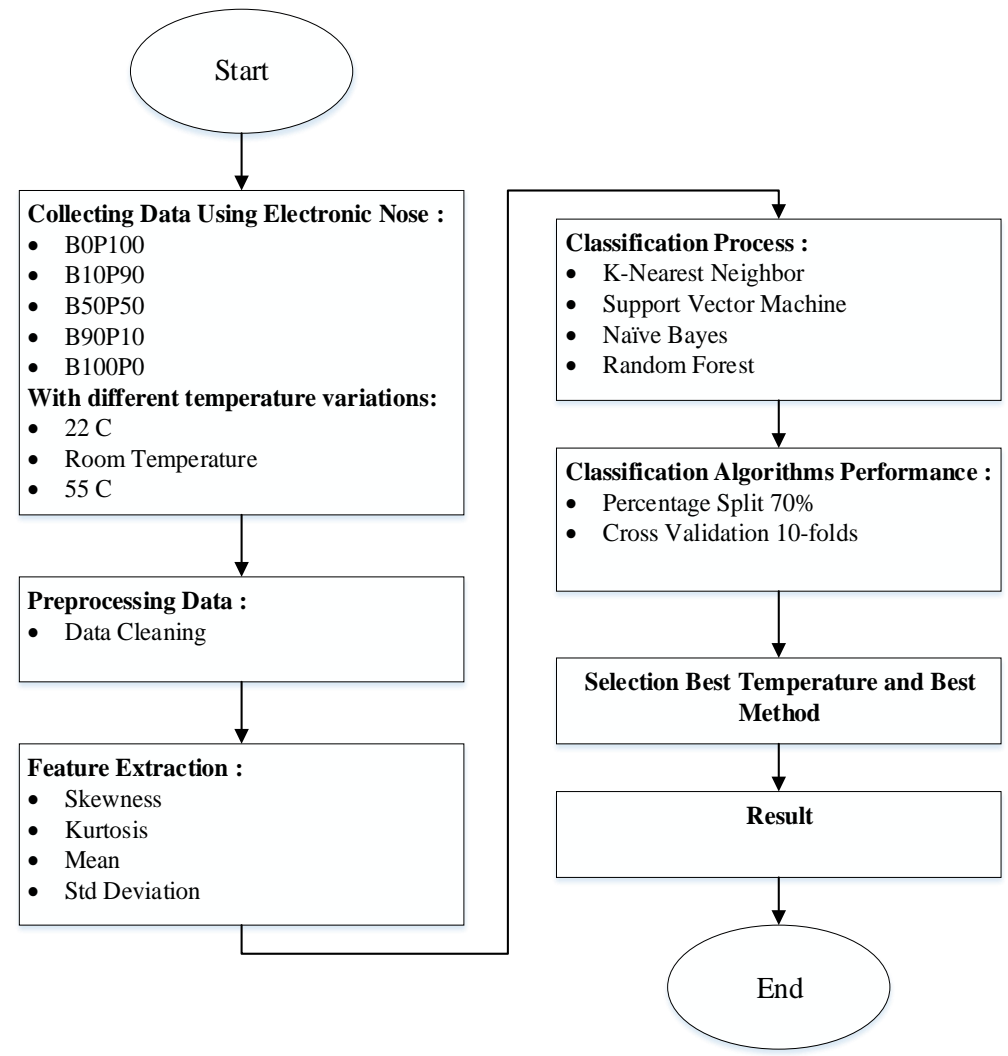

Figure 1. The proposed method

\subsection{Collecting data using electronic nose}

Data collection was done using electronic nose divided into 5 variations of meat and 3 temperature variations. Table 1 is a detailed composition of the data collection scenario.

\section{Table 1. Scenario of data collection}

\begin{tabular}{cccccc}
\hline Code & Beef & Pork & \multicolumn{3}{c}{ Temperature } \\
& & & $-22^{\circ} \mathrm{C}$ & Room Temp. & $55^{\circ} \mathrm{C}$ \\
\hline B0P100 & $0 \%$ & $100 \%$ & $\checkmark$ & $\checkmark$ & $\checkmark$ \\
B10P90 & $10 \%$ & $90 \%$ & $\checkmark$ & $\checkmark$ & $\checkmark$ \\
B50P50 & $50 \%$ & $50 \%$ & $\checkmark$ & $\checkmark$ & $\checkmark$ \\
B90P10 & $90 \%$ & $10 \%$ & $\checkmark$ & $\checkmark$ & $\checkmark$ \\
B100P0 & $100 \%$ & $90 \%$ & $\checkmark$ & $\checkmark$ & $\checkmark$ \\
\hline
\end{tabular}

\subsection{Preprocessing data}

Researchers apply data cleaning at the preprocessing level. Data cleaning is the method of eliminating redundant data, verifying incompatibility data and correcting data errors, such as write errors [6]. Information derived from all experimental tests usually has incomplete contents such as missing data, incorrect data or even a typo [7]. Additionally, there are data attributes which are not important to the theory of data mining. Cleaning up data would also impact the efficiency of data mining, as the data handled would reduce number and complexity [8].

Temperature effect of electronic nose sampling for classifying mixture ... (Sinarring Azi Laga) 


\subsection{Feature extraction}

To determine whether or not the research is being performed properly, the first thing that must be ascertained is whether or not the data is usually transmitted. The sum of statistical metrics used in the features of the extraction phases is the sum of the kurtosis, skewedness, mean and stdev measured using the Microsoft Excel software.

\subsubsection{Kurtosis}

Kurtosis is a function of how smooth the upper section of the symmetric distribution compared with the same variant's normal distribution [9]. In fact, the score on the distribution tail is more affected by kurtosis than the fulfillment center score. In general, this is contrasted with regular distribution that has a kurtosis factor 3, named mesokurtic [10]. Symmetric distribution, with a coefficient of under 3 with a incisive peak, is named leptokurtic, whereas it is called platicurtic a distribution characterized by a flat apex, which has a kurtosis factor greater than 3 [11]. The following is the Kurtosiss equation:

$$
\operatorname{Kurtosis}(K)=\frac{1}{T \sigma^{4}} \sum_{t=1}^{T}\left(T_{t}-\mu\right)^{4}
$$

\subsubsection{Skewness}

Skewness is the pendulum of a data frequency curve for the distribution [12]. Below are two models of skewed positives and negatives. Positive slope, the slope of a data distribution frequency curve tends to be far to the left of the medium (value below the median) [13]. Therefore, the slope of the tail over the frequency curve is to the right. Likewise, the tail of frequency curve slopes in a negative slope is more to the left [14]. As shown in (2) is the formula of skewness, where the rt value for each data observed is, $\ddot{y}$ is the sample data standard deviation, $\mu$ is the sample data average and $\mathrm{T}$ is the number of observations.

$$
\operatorname{Skewness}(S)=\frac{1}{T \sigma^{34}} \sum_{t=1}^{T}\left(r_{t}-\mu\right)^{3}
$$

\subsubsection{Mean}

Mean is the mechanism on which the signal frequency will be centered, summarizing all sample data communities then divided by the sample number [15]. As shown in (3) is a skewness formula, where r2 is the value of any observed data, and $\mathrm{T}$ is the number of observed samples.

$$
\operatorname{Mean}(\mu)=\frac{1}{T} \sum_{t-1}^{T} r 2
$$

\subsubsection{Std. deviation}

The strong value of $\sigma$ implies that the data meaning is sprayed from its mid-range $\mu$. If $\sigma$ is small, the resulting value is grouped to the mean value [16]. As shown in (4) is a skewness formula, where $\mathrm{r} 2$ reflects the importance of every object observed, $\mu$ is the sample item average and $\mathrm{T}$ is the number of samples.

$$
\text { Variansi }\left(\sigma^{2}\right)=\frac{1}{T} \sum_{t=1}^{T}(r 2-\mu)^{2}
$$

\subsection{Classification}

The classification process was divided into two phases: learning \& test. In the learning phase, part of the data that was known for the data class was fed to form an approximate model [17]. Then in the test phase the model that had been formed was tested with some other data to determine the accuracy of the model. If the accuracy is sufficient this model can be used for predicting unknown classes of data. In this study there are 4 scenarios for data classification, namely:

- Scenario 1 (k-Nearest Neighbor method)

- Scenario 2 (Support Vector Machine method)

- Scenario 3 (Naïve Bayes method)

- Scenario 4 (Random Forest method)

\subsection{Selection best temperature and best method}

After getting the classification results from the 4 existing scenarios, the next step is to classify the ROC value of the area to the temperature and method [18]. The ROC curve is widely used to assess prediction results. The ROC curve is a two-dimensional tool used to assess classification performance using two decision classes, each object mapped to one element of a pair of pairs, positive or negative [19]. For data mining classification according to Gorunescu, the AUC value or Area under the curve that is often used as the sum of the ROC curves and as a measure of performance classifiers can be divided into several groups [20]: 
- $\quad 0.90-1.00=$ Excellent Classification

- $\quad 0.80-0.90=$ Good Classification

- $0.70-0.80=$ Fair Classification

- $0.60-0.70=$ Poor Classification

- $0.50-0.60=$ Failure

\section{RESULTS AND ANALYSIS}

In this sub-chapter, we discuss the classification testing on each data that has been obtained from electronic nose and evaluation of results

\subsection{Scenario 1 testing (K-NN method)}

In this testing scenario, a meat classification trial was conducted using the k-Nearest Neighbor method with 5 variations of meat with 3 different variations in temperature. In the testing of scenario 1 , it was achieved by splitting data from the extraction function into training data and testing data with a ratio of $30 \%$, and $\mathrm{k}=3$ as shown in Table 2. Detail accuration using K-NN method can be seen on Figure 2.

Table 2. Confussion matrix using K-NN method

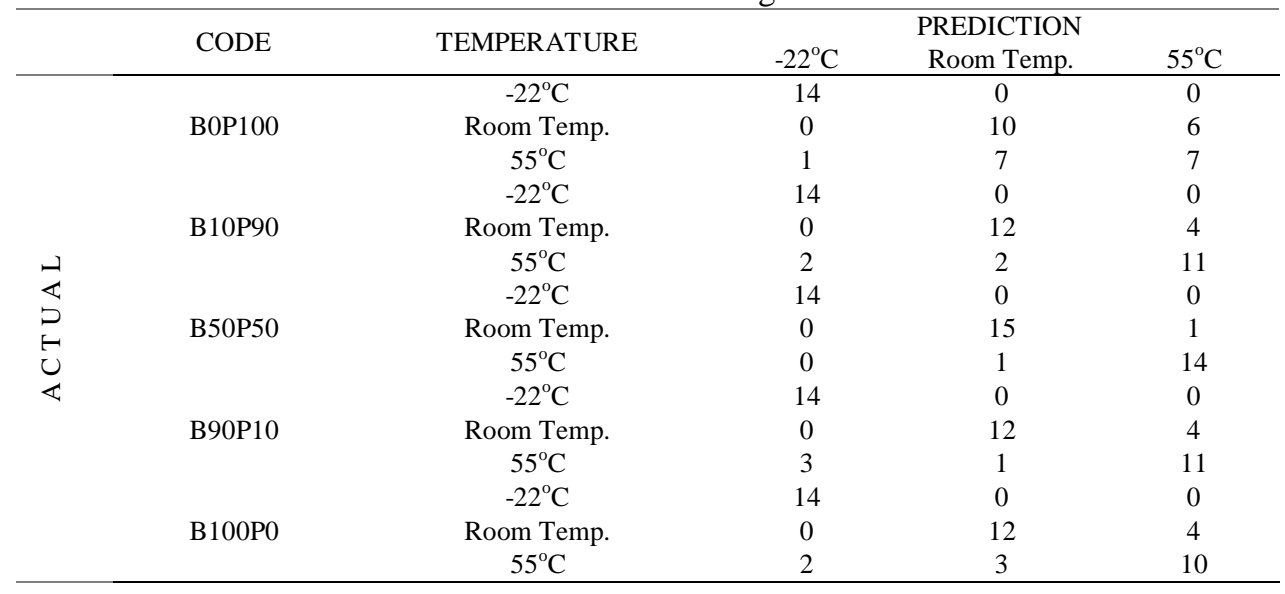

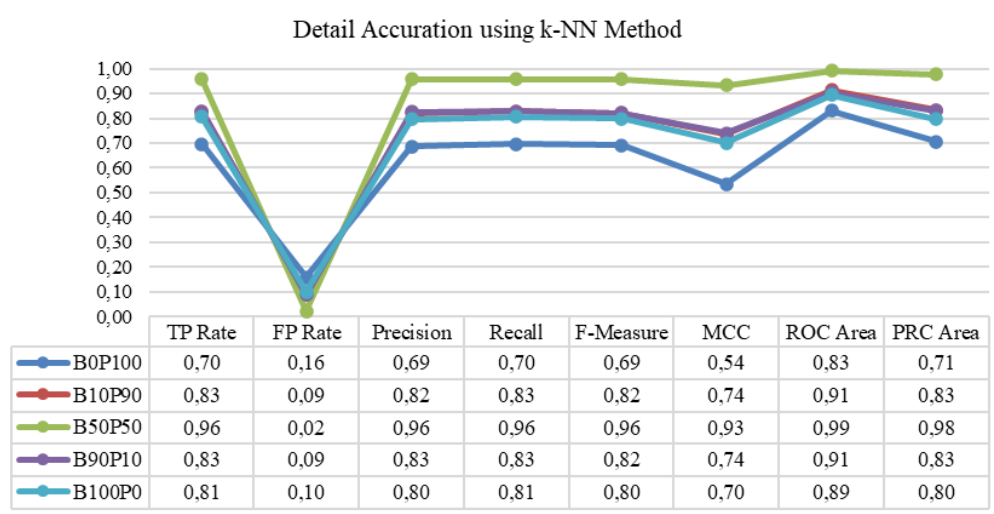

Figure 2. Detail accuration using K-NN method

\subsection{Scenario 2 testing (SVM Method)}

In this test scenario, a meat classification trial was conducted using the Support Vector Machine method with 5 variations of meat with 3 different variations in temperature as shown in Table 3 . In the testing of scenario 2, this was performed using k-fold cross-validation, with $\mathrm{k}=10$ for the RBF kernel. The aim of testing using $\mathrm{k}$-fold cross-validation is to pick the right temperature parameters according to the highest precision, so that the precision of SVM purity classification can be improved [21]. Detail Accuration using SVM Method as shown in Figure 3. 
Table 3. Confussion matrix SVM method

\begin{tabular}{|c|c|c|c|c|c|}
\hline & \multirow{2}{*}{ CODE } & \multirow{2}{*}{ TEMPERATURE } & \multicolumn{3}{|c|}{ PREDICTION } \\
\hline & & & $-22^{\circ} \mathrm{C}$ & Room Temp. & $55^{\circ} \mathrm{C}$ \\
\hline \multirow{15}{*}{ 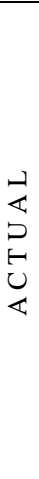 } & \multirow{3}{*}{ B0P100 } & $-22^{\circ} \mathrm{C}$ & 43 & 2 & 5 \\
\hline & & Room Temp. & 8 & 32 & 10 \\
\hline & & $55^{\circ} \mathrm{C}$ & 15 & 11 & 24 \\
\hline & \multirow{3}{*}{ В10P90 } & $-22^{\circ} \mathrm{C}$ & 47 & 1 & 2 \\
\hline & & Room Temp. & 6 & 39 & 5 \\
\hline & & $55^{\circ} \mathrm{C}$ & 20 & 7 & 23 \\
\hline & \multirow{3}{*}{ B50P50 } & $-22^{\circ} \mathrm{C}$ & 50 & 0 & 0 \\
\hline & & Room Temp. & 2 & 39 & 9 \\
\hline & & $55^{\circ} \mathrm{C}$ & 4 & 10 & 36 \\
\hline & \multirow{3}{*}{ B90P10 } & $-22^{\circ} \mathrm{C}$ & 40 & 8 & 2 \\
\hline & & Room Temp. & 6 & 39 & 5 \\
\hline & & $55^{\circ} \mathrm{C}$ & 17 & 6 & 27 \\
\hline & \multirow{3}{*}{$\mathrm{B} 100 \mathrm{P} 0$} & $-22^{\circ} \mathrm{C}$ & 48 & 2 & 0 \\
\hline & & Room Temp. & 5 & 39 & 6 \\
\hline & & $55^{\circ} \mathrm{C}$ & 15 & 8 & 27 \\
\hline
\end{tabular}

Detail Accuration using SVM Method

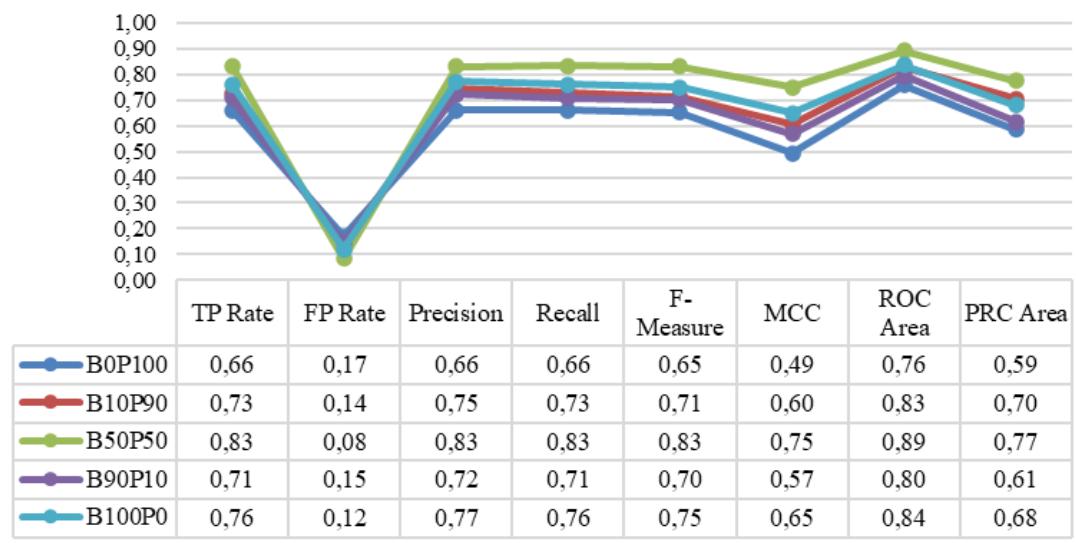

Figure 3. Detail Accuration using SVM Method

\subsection{Scenario 3 testing (naïve bayes method)}

In this testing scenario, a meat classification trial was conducted using the Naïve Bayes method with 5 variations of meat with 3 different temperature variations. Naive Bayes calculates destiny possibility predictions from facts or studies that had been given, based at the opportunity point ofview [22]. In the testing of scenario 3, k-fold cross-validation was used, with $\mathrm{k}=10$ as shown in Table 4. Detail accuration using naïve bayes method as shown in Figure 4.

Table 4. Confussion matrix naïve bayes method

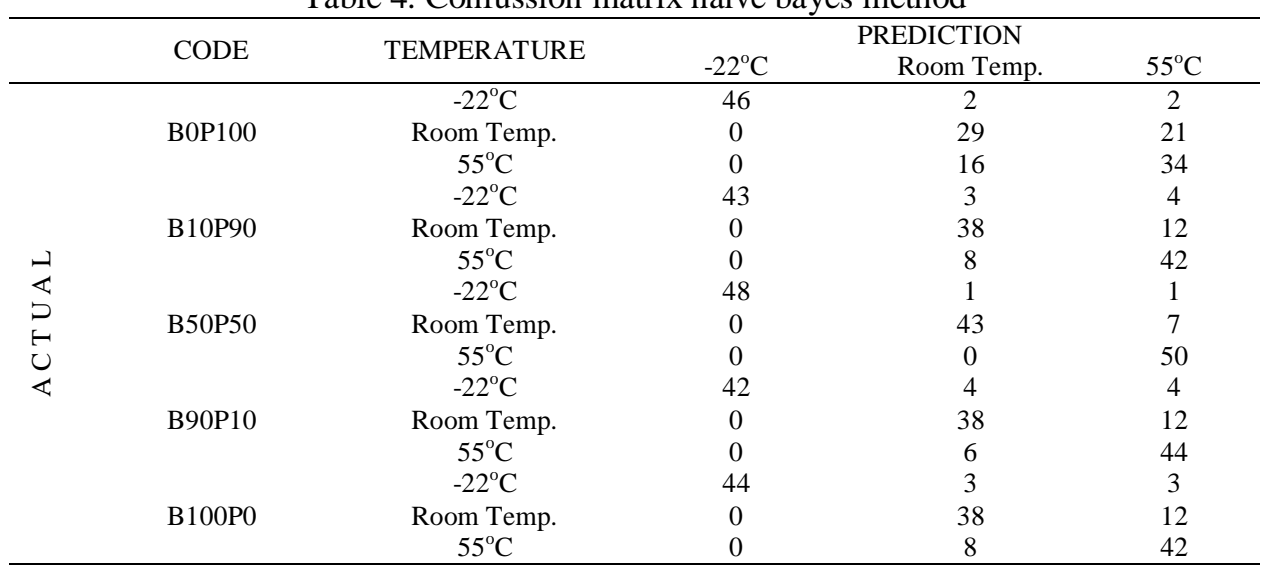


Detail Accuration using Naive Bayes Method

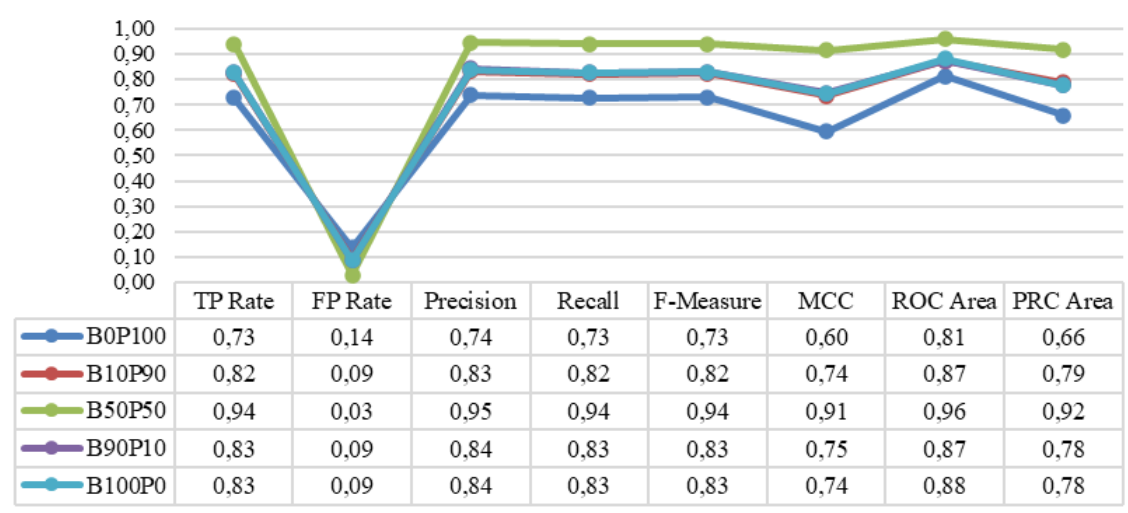

Figure 4. Detail accuration using naïve bayes method

\subsection{Scenario 4 testing (random forest method)}

In this test scenario, a meat classification trial was conducted using the random forest method with 5 variations of meat with 3 variations in temperature. Random forest have developed as genuine competitors to state-of-the-art strategies such as boosting [23] and back vector machines [24]. In the testing of this scenario, $\mathrm{k}$-fold cross-validation was used, with $\mathrm{k}=10$ as shown in Table 5. Detail accuration using random forest method as shown in Figure 5.

Table 5. Confussion Matrix Random Forest Method

\begin{tabular}{|c|c|c|c|c|c|}
\hline & \multirow{2}{*}{ CODE } & \multirow{2}{*}{ TEMPERATURE } & \multicolumn{3}{|c|}{ PREDICTION } \\
\hline & & & $-22^{\circ} \mathrm{C}$ & Room Temp. & $55^{\circ} \mathrm{C}$ \\
\hline \multirow{15}{*}{ 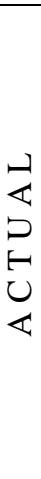 } & \multirow{3}{*}{ B0P100 } & $-22^{\circ} \mathrm{C}$ & 49 & 1 & 0 \\
\hline & & Room Temp. & 0 & 26 & 24 \\
\hline & & $55^{\circ} \mathrm{C}$ & 0 & 27 & 23 \\
\hline & \multirow{3}{*}{ B10P90 } & $-22^{\circ} \mathrm{C}$ & 49 & 0 & 1 \\
\hline & & Room Temp. & 0 & 35 & 15 \\
\hline & & $55^{\circ} \mathrm{C}$ & 0 & 14 & 36 \\
\hline & \multirow{3}{*}{ B50P50 } & $-22^{\circ} \mathrm{C}$ & 50 & 0 & 0 \\
\hline & & Room Temp. & 0 & 44 & 6 \\
\hline & & $55^{\circ} \mathrm{C}$ & 0 & 6 & 42 \\
\hline & \multirow{3}{*}{ B90P10 } & $-22^{\circ} \mathrm{C}$ & 49 & 1 & 0 \\
\hline & & Room Temp. & 0 & 35 & 15 \\
\hline & & $55^{\circ} \mathrm{C}$ & 0 & 14 & 36 \\
\hline & \multirow{3}{*}{$\mathrm{B} 100 \mathrm{P} 0$} & $-22^{\circ} \mathrm{C}$ & 49 & 1 & 0 \\
\hline & & Room Temp. & 0 & 33 & 17 \\
\hline & & $55^{\circ} \mathrm{C}$ & 0 & 16 & 34 \\
\hline
\end{tabular}

Detail Accuration using Random Forest Method

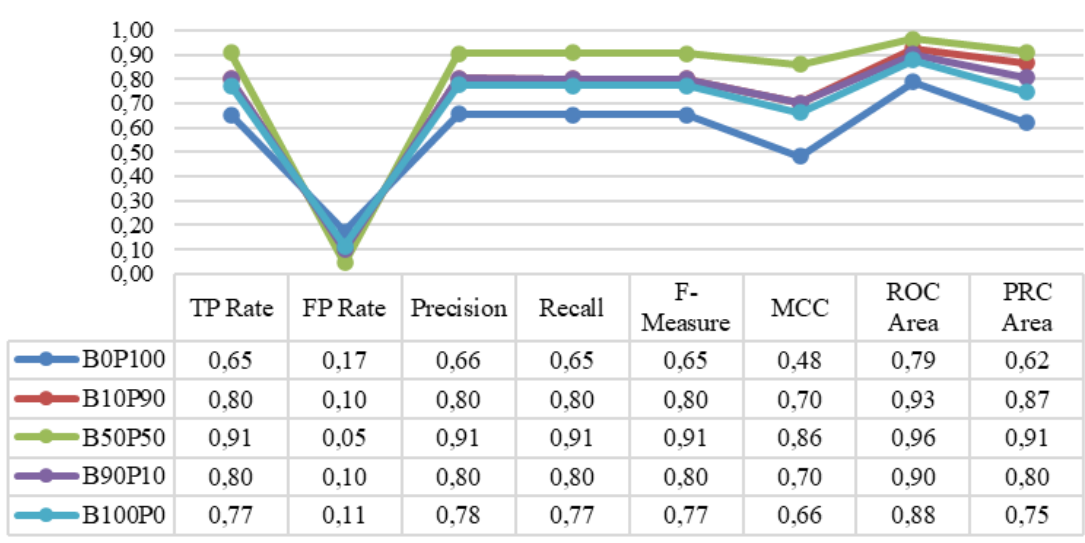

Figure 5. Detail accuration using random forest method

Temperature effect of electronic nose sampling for classifying mixture ... (Sinarring Azi Laga) 


\subsection{ROC values based on temperature and method}

A receiver operating characteristics (ROC) graph is atechnique for visualizing, organizing and selecting classifi-ers based on their execution [25]. To find the temperature and the best method in this experiment, the researcher grouped the ROC values against the method and temperature as in Table 6 . At $-22^{\circ} \mathrm{C}$, the method that has the highest accuracy is the random forest method with an average value of ROC 1.000. While the method that has the second highest accuracy is the k-Nearest Neighbor method with an average value of ROC 0.986. The naïve bayes method is ranked 3rd with an average value of ROC 0.971 and the SVM method is the method that has the lowest accuracy with an average ROC value of 0.872 . At room temperature, the method that has the highest accuracy is the k-Nearest Neighbor method with an average value of ROC 0.886 . While the method that has high accuracy to 2 is the Naïve Bayes method with an average ROC value of 0.856 . The Random Forest method is ranked 3rd with an average value of ROC 0.839 and the SVM method is the method that has the lowest accuracy with an average ROC value of 0.820. At $55^{\circ} \mathrm{C}$, the method that has the highest accuracy is the Naïve Bayes method with an average ROC value of 0.864. While the method that has the second highest accuracy is the K-Nearest Neighbor method with an average value of ROC of 0.848 . The Random Forest method is ranked 3rd with an average value of ROC 0.836 and the SVM method is the method that has the lowest accuracy with an average value of ROC 0.774

Table 6. ROC area value sort by methods and code

\begin{tabular}{|c|c|c|c|c|c|c|c|}
\hline Temp & Method & Code & ROC Value & Temp & Method & Code & ROC Value \\
\hline \multirow{24}{*}{$-22^{\circ} \mathrm{C}$} & \multirow[t]{5}{*}{ k-NN } & S0B100 & 0.99 & & & S0B100 & 0.77 \\
\hline & & S10B90 & 0.98 & & \multirow{3}{*}{$\mathrm{k}-\mathrm{NN}$} & S10B90 & 0.90 \\
\hline & & S50B50 & 1 & & & S50B50 & 0.98 \\
\hline & & S90B10 & 0.97 & & & S90B 10 & 0.90 \\
\hline & & S100B0 & 0.98 & & & S100B0 & 0.85 \\
\hline & \multicolumn{2}{|c|}{ Average of ROC Value } & 0.98 & & \multicolumn{2}{|c|}{ Average of ROC Value } & 0.88 \\
\hline & \multirow[t]{5}{*}{ SVM } & S0B100 & 0.85 & & \multirow{4}{*}{ SVM } & SoB 100 & 0.74 \\
\hline & & S10B90 & 0.84 & & & S10B90 & 0.86 \\
\hline & & S50B50 & 0.98 & & & S50B50 & 0.84 \\
\hline & & S90B10 & 0.78 & & & S90B10 & 0.81 \\
\hline & & $\mathrm{S} 100 \mathrm{~B} 0$ & 0.88 & & & $\mathrm{~S} 100 \mathrm{~B} 0$ & 0.83 \\
\hline & \multicolumn{2}{|c|}{ Average of ROC Value } & 0.87 & Room & \multicolumn{2}{|c|}{ Average of ROC Value } & 0.82 \\
\hline & Naïve & S0B100 & 0.97 & Temp & \multirow{5}{*}{$\begin{array}{l}\text { Naïve } \\
\text { bayes }\end{array}$} & S0B100 & 0.73 \\
\hline & \multirow[t]{4}{*}{ bayes } & S10B90 & 0.93 & & & S10B90 & 0.84 \\
\hline & & S50B50 & 0.99 & & & S50B50 & 0.93 \\
\hline & & S90B10 & 0.99 & & & S90B10 & 0.93 \\
\hline & & S100B0 & 0.96 & & & S100B0 & 0.82 \\
\hline & \multicolumn{2}{|c|}{ Average of ROC Value } & 0.97 & & \multicolumn{2}{|c|}{ Average of ROC Value } & 0.85 \\
\hline & Random & S0B100 & 1 & & & S0B100 & 0.68 \\
\hline & \multirow[t]{4}{*}{ Forest } & S10B90 & 0.99 & & \multirow{4}{*}{$\begin{array}{c}\text { Random } \\
\text { Forest }\end{array}$} & S10B90 & 0.90 \\
\hline & & S50B50 & 1 & & & S50B50 & 0.94 \\
\hline & & S90B10 & 1 & & & S90B10 & 0.84 \\
\hline & & S100B0 & 1 & & & S100B0 & 0.82 \\
\hline & \multicolumn{2}{|c|}{ Average of ROC Value } & 1 & & Average & ROC Value & 0.83 \\
\hline
\end{tabular}

\begin{tabular}{|c|c|c|c|}
\hline Temp & Method & Code & ROC Value \\
\hline \multirow{24}{*}{$55^{\circ} \mathrm{C}$} & \multirow{5}{*}{$\mathrm{k}-\mathrm{NN}$} & S0B100 & 0.73 \\
\hline & & S10B90 & 0.85 \\
\hline & & S50B50 & 0.98 \\
\hline & & S90B10 & 0.83 \\
\hline & & $\mathrm{S} 100 \mathrm{~B} 0$ & 0.83 \\
\hline & \multicolumn{2}{|c|}{ Average of ROC Value } & 0.84 \\
\hline & \multirow{4}{*}{ SVM } & S0B100 & 0.66 \\
\hline & & S10B90 & 0.78 \\
\hline & & S50B50 & 0.84 \\
\hline & & S90B 10 & 0.78 \\
\hline & & S100B0 & 0.79 \\
\hline & \multicolumn{2}{|c|}{ Average of ROC Value } & 0.77 \\
\hline & & S0B100 & 0.73 \\
\hline & \multirow{3}{*}{$\begin{array}{l}\text { Naïve } \\
\text { bayes }\end{array}$} & S10B90 & 0.83 \\
\hline & & S50B50 & 0.94 \\
\hline & & S90B 10 & 0.94 \\
\hline & & S100B0 & 0.85 \\
\hline & \multicolumn{2}{|c|}{ Average of ROC Value } & 0.86 \\
\hline & \multirow{5}{*}{$\begin{array}{c}\text { Random } \\
\text { Forest }\end{array}$} & S0B100 & 0.67 \\
\hline & & S10B90 & 0.88 \\
\hline & & S50B50 & 0.94 \\
\hline & & S90B 10 & 0.86 \\
\hline & & S100B0 & 0.81 \\
\hline & \multicolumn{2}{|c|}{ Average of ROC Value } & 0.83 \\
\hline
\end{tabular}

Indonesian J Elec Eng \& Comp Sci, Vol. 19, No. 3, September 2020 : 1626 - 1634 


\subsection{Comparison of methods to temperature}

After obtaining the average of each ROC value, the next step is to compare the 4 methods used with 3 temperature variations can be seen on Table 7 and Figure 6.

Table 7. Comparison of methods to temperature

\begin{tabular}{ccccc}
\hline & k-NN & SVM & Naïve Bayes & Random Forest \\
\hline -22 C & 0.986 & 0.872 & 0.971 & 1.000 \\
Room Temp. & 0.886 & 0.821 & 0.856 & 0.839 \\
55 C & 0.848 & 0.774 & 0.864 & 0.836 \\
\hline
\end{tabular}

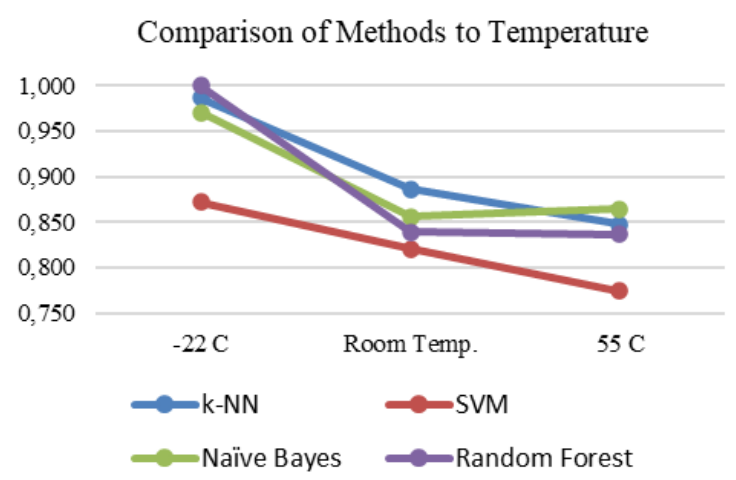

Figure 6. Comparison of methods to temperature

\section{CONCLUSION}

Based on the results of the research conducted by the author, the following conclusions are obtained: The researcher divided the experiment into 4 scenarios with each composition 5 variations of meat (Beef $0 \%$ - Pork 100\%, Beef 10\% - Pork 90\%, Beef 50\% - Pork 50\%, Beef 90\% - Pork 10\% and Beef 100\% - Pork 0\%) with 3 temperature variations $\left(-22^{\circ} \mathrm{C}\right.$, Room Temperature, and $\left.55^{\circ} \mathrm{C}\right)$, namely: a. k-Nearest Neighbor Method, b. Support Vector Machine Method, c. Naïve Bayer Method, d. Random Forest Method. There is an effect of temperature on increasing accuracy, which is at $-22^{\circ} \mathrm{C}$. Because the lower the temperature the more stable the value obtained by electronic nose is.

The following are methods that have high accuracy based on temperature: a) At $-22^{\circ} \mathrm{C}$, the sequence of methods that has the highest to lowest accuracy is Random Forest with an average value of ROC 1.00; KNearest Neighbor with an average value of ROC 0.986; Naïve Bayes with an average value of ROC 0.971 and Support Vector Machine with an average ROC value of 0.872. b) At room temperature, the method sequence has the highest to lowest accuracy, namely K-Nearest Neighbor with an average value of ROC 0.886; Naïve Bayes with an average value of ROC 0.856; Random Forest with an average value of ROC 0.839 and Support Vector Machine with an average ROC value of 0.821 . c) At $55^{\circ} \mathrm{C}$, the sequence of methods has the highest to lowest accuracy, namely Naïve Bayes with an average ROC value of 0.864 ; KNearest Neighbor with an average value of ROC 0.848; Random Forest with an average value of ROC 0.836 and Support Vector Machine with an average value of ROC 0.774 .

\section{ACKNOWLEDGEMENTS}

The authors wish to express gratitude to the Sekolah Tinggi Ilmu Ekonomi Perbanas, Institut Teknologi Sepuluh Nopember, and Directorate General of Higher Education, Ministry of Education and Culture of the Republic of Indonesia for promoting this research.

\section{REFERENCES}

[1] S. A. Laga and R. Sarno, "Optimal Sample Temperature of Electronic Nose For Detecting Beef And Pork Mixture," in International Conference on Information and Communications Technology (ICOIACT), 2019.

[2] Y. Erwanto, M. Z. Abidin, E. Y. P. M. Sugiyono and A. Rohman, "Identification of Pork Contamination in Meatballs of Indonesia Local Market Using Polymerase Chain Reaction-Restriction Fragment Length Polymorphism (PCR-RFLP) Analysis," Asian-Australas J Anim Sci, 2014. 
[3] S. Ong, M. Zuraini, M. Jurin, Y. Cheah, R. Tunung, L. Chai, Y. Haryani, F. Ghazali and R. Son, "Meat molecular detection : sensitivity of polymerase chain reaction-restriction fragment length polymorphism in species differentiation of meat from animal origin," Asean Food Journal, pp. 51-59, 2007.

[4] R. Sarno and D. R. Wijaya, "Recent Development in Electronic Nose Data Processing for Beef Quality Assessment," TELKOMNIKA, vol. 17, pp. 337-448, 2019.

[5] D. R. Wijaya, R. Sarno, E. Zulaika and S. I. Sabilla, "Development of mobile electronic nose for beef quality monitoring," in Information Systems International Conference (ISICO), 2017.

[6] M. D. Potter, Principle of Meat Science 2th, Lowa: Publishing Co, 1993.

[7] S. Naruki and S. Kononi, Kimia Teknologi Pengolahan Hasil Hewan, Universitas Gadjah Mada, 1992.

[8] M. Nurjuliana, Y. B. Che Man and D. Mat Hashim, "Analysis of lard's aroma by an electronic nose for rapid Halal authentication," JAOCS, J.Am. Oil Chem. Soc, vol. 88, pp. 75-82, 2011.

[9] D. R. Wijaya, R. Sarno and E. Zulaika, "Noise filtering framework for electronic nose signals: An application for beef quality monitoring," Elsevier, Computers and Electronics in Agriculture, vol. 157, pp. 305-321, 2019.

[10] I. H. Witten, E. Frank and M. A. Hall, "Data Mining Practical Machine Learning Tools and Trchniques (3rd ed)," USA: Elsevier, 2011.

[11] D. L. Hanselman, "Mastering Matlab 5, A Comprehensive Tutorial and Reference," Prentice-Hall Inc, 1998.

[12] A. Mcandrew, "An Introduction to Digital Image Processing with Matlab," Australia: Thomson, 2004.

[13] D. B. Magfira and R. Sarno, "Classification of Arabica and Robusta Coffee using Electronic Nose," in International Conference on Information and Communications Technology (ICOIACT), pp. 645-650, 2018.

[14] S. I. Sabila, R. Sarno and J. Siswantoro, "Estimating Gas Concentration using Artificial Neural Network for Electronic Nose," in Information Systems International Conference (ISICO), 2017.

[15] S. I. Sabilla and R. Sarno, "Development of Wavelet Transforms to Predict Methane in Chili using The Electronic Nose," International Conference on Advanced Mechatronics, Intelligent Manufacture, and Industrial Automation (ICAMIMIA), pp. 271-276, 2017.

[16] H. Ankarali, A. C. Yazici and S. Ankarali, "A bootstrap confidence interval for skewnessand kurtosis and properties of t-test in small samples from normal distribution," Balkan Medical Journal, vol. 26, no. 4, 2009.

[17] D. R. Wijaya, R. Sarno and A. F. Daiva, "Electronic Nose for Classifying Beef and Pork using Naïve Bayes Method," in International Seminar on Sensors, Instrumentation, Measurement and Metrology (ISSIMM), pp. 104-108 2017.

[18] R. Sarno and D. R. Wijaya, "Detection of Diabetes from Gas Analysis of Human Breath using E-Nose," in International Conference on Information \& Communication Technology and Systems (ICTS), pp. 241-246, 2017.

[19] S. A. Laga and R. Sarno, "Time and Cost Optimization using Goal Programming and Priority Scheduling," in International Seminar on Application for Technology of Information and Communication (iSemantic), 2018.

[20] M. Jupri and R. Sarno, "Taxpayer Compliance Classification Using C4.5, SVM, KNN, Naive Bayes and MLP," in 2018 International Conference on Information and Communications Technology (ICOIACT), pp. 297-303, 2018.

[21] B. Y. Pratama and R. Sarno, "Personality classification based on Twitter text using Naive Bayes, KNN and SVM," in International Conference on Data and Software Engineering (ICoDSE), pp. 170-174, 2015.

[22] R.A.Laksono, K.R. Sungkono and R.Sarno, "Sentiment Analysis of Restaurant Customer Reviews on TripAdvisor using Naive Bayes," in 12th International Conference on Information \& Communication Technology and System (lCTS) 2019, pp. 49-54, 2019.

[23] Y. Freund and R. Shapire. Experiments with a new boosting algorithm. In L. Saitta, editor, Machine Learning: Proceedings of the 13th International Conference, pages 148-156, San Francisco, 1996. Morgan Kaufmann.

[24] J. Shawe-Taylor and N. Cristianini. Kernel Methods for Pattern Analysis. Cambridge University Press, Cambridge, 2004.

[25] D. L. Streiner, J. Cairney. "What's Under the ROC? An Introduction to Reciever Operating Characteristics Curves," The Canadian Journal of Psychiatry, vol. 52, no. 2, 2007.

\section{BIOGRAPHIES OF AUTHORS}

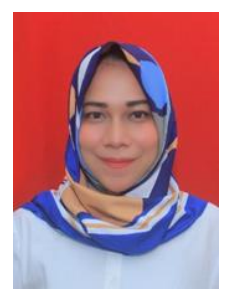

Sinarring Azi Laga is a graduated student of Department of Information Technology Management, Faculty of Bussiness and Technology Management, Intitut Teknologi Sepuluh Nopember. Her current interest are in Data Mining, Machine Learning and Decision Making. Email: sinarringazil@gmail.com

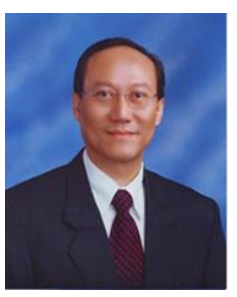

Riyanarto Sarno received M.Sc and Ph.D in Computer Science from the University of Brunswick Canada in 1988 and 1992. In 2003 he was promoted to a Full Professor. His teaching and research interests includes Internet of Things, Process Aware Information Systems, Intelligent Systems and Business Process Management. E-mail: riyanarto@if.its.ac.id 